AJHSE Vol: 1 (1): 81-92, 2020

Article Ref. No.: AJHSE-0101-05

Accepted Date: Apr. 01, 2020

(C) 2020. CC License 4.0

www.ajhse.org

\title{
ASSOCIATION BETWEEN SELECTED TUMOUR MARKERS AND CERVICAL INTRAEPITHELIAL NEOPLASM AMONG WOMEN IN BENIN CITY, NIGERIA
}

\author{
${ }^{* 1,2}$ Atoe, K. and ${ }^{3}$ Idemudia, O. J.
}

${ }^{1}$ Deptment of Chemical Pathology, Edo University, Iyamho, Edo State, Nigeria

${ }^{2}$ Applied Environmental Bioscience and Public Research Group, University of Benin, Benin City, Nigeria

${ }^{3}$ Dept. Chemical Pathology, University of Benin, Benin City, Nigeria

*Email: atoe.kenneth@edouniversity.edu.ng

\begin{abstract}
$\mathrm{F}$ Temale mortality rate due to cervical cancer is on the increase in developing countries like Nigeria. Early detection of premalignant lesions in the cervix is critical in increasing the chances of survival. This requires an effective primary screening mechanism before the onset of clinical symptoms. The purpose of this study was to investigate the capacity of three biomarkers; Cancer Antigen 125 (CA125), Cancer Antigen 15.3 (CA15.3) and Carcinoembryonic Antigen (CEA) in the diagnosis of Cervical Intraepithelial Neoplasm (CIN). The study, which was a cross-sectional prospective study, was carried out at the Department of Obstetrics and Gynaecology, University of Benin Teaching Hospital Benin City and Department of Chemical Pathology, Edo University Iyamho, Edo state Nigeria, between August 2017 and January 2019. A total of 197 female participants were recruited and grouped into; Negative, CIN 1, CIN 2 and CIN 3 based on histological diagnosis. Venous blood was obtained from participants and serum CA125, CA15.3 and CEA levels were determined using standardized laboratory methods. The results showed a significant elevation in serum CA125, CA15.3 and CEA levels with CIN 3 lesions $(17.81 \mathrm{ng} / \mathrm{ml}, 49.46 \mathrm{ng} / \mathrm{ml}$ and $17.43 \mathrm{ng} / \mathrm{ml}$ respectively) compared to their counterpart healthy individuals $(8.89 \mathrm{ng} / \mathrm{ml}, 32.18 \mathrm{ng} / \mathrm{ml}$ and $11.57 \mathrm{ng} / \mathrm{ml}$ respectively). The markers presented low sensitivities $(0-54.47 \%)$ and high specificities $(98.11-100.00 \%)$ when compared with gold standard (histological diagnosis).
\end{abstract}

Keywords: Cancer antigen, Carcinoembryonic antigen, CA15.3, CA125, Cancer, Cervix, Intraepithelial Neoplasm

LICENSE: This article by African Journal of Health, Safety and Environment (AJHSE)is licensed and published under the Creative Commons Attribution License 4.0 International License, which permits unrestricted use, distribution, and reproduction in any medium, provided this article is duly cited.

COPYRIGHT: The Author(s) completely retain the copyright of this published article.

OPEN ACCESS: The Author(s) approves that this article remains permanently online in the open access (OA) mode.

QA: This Article is published in line with "COPE (Committee on Publication Ethics) and PIE (Publication Integrity \& Ethics)". 


\section{INTRODUCTION}

Cervical cancer is the third most common tumour in women worldwide with more than $80 \%$ of the cases occurring in developing countries (Ferlay et al., 2008). Almost all cervical cancers are caused by infections with human papillomavirus (HPV) (Arbyn et al., 2011). It has been reported that aggressive cervical tumour advances from a precancerous state called Cervical Intraepithelial Neoplasm (CIN) when infection with a high-risk HPV has continued for about 13 years (WHO, 2010). In population-wide screening programs, the use of the gold standard method (Pap smear) has recorded success in the reduction of cases of full-blown cervical cancers but not without limitations. The possibility of slightly abnormal tests, inconvenience of repeated Pap smear and accuracy of results that are based on personnel interpretation are concerns that require specific innovative solutions. Through the availability of new technologies, researchers have increased efforts to develop novel biomarkers for early diagnosis and monitoring of therapeutic treatments (Goncalves et al., 2017). The establishment of an ideal serum biomarker for CIN will increase the chances of early diagnostic accuracy, one-time sample collection, and treatment efficacy with decreased reoccurrence.

Tumor markers for this sort of condition are elaborated by tumor cells either due to the cause or effect of malignant processes (Vaccarella et al., 2013). These can be used as biomarkers for the diagnosis of cervical intraepithelial lesions. The study of the pattern or status of serum tumor markers in CIN patients has the potential for reducing female mortality rate in Nigeria caused by late and inaccurate diagnosis of CIN. A biomarker present in substantial amount may indicate the presence of a cancer (Bosch et al., 2008). They may be present as intracellular substances or released into the blood and appear in the serum (Jastreboff and Cymet, 2002). Ongoing research for appropriate tumor markers in serum, tissue and body fluids during neoplastic progression is of clinical importance in the management of patients with various malignancies (Jemal et al., 2012). The challenge in developing countries like Nigeria is the identification and verification of appropriate tumor marker for specific types of malignancies. The range of biochemical tumor markers recounted to date is extensive; some of these can be broadly classified as Oncofetal antigens such as alpha-fetoprotein (AFP) and Carcinoembryonic antigen (CEA); Tumor-related antigens such as CA125, CA19-9 and CA15-3; as well as hormones. Examples of hormones include beta-human chorionic gonadotropin, calcitonin and placental lactogen. Hormone receptors are also examples of available tumor marker, including estrogen and progesterone receptors (Dasari et al., 2015).

The choice of tumor markers selected for this study was based on reports of their specificity to the female reproductive organs and curious thought of the possible interaction between the tissues of the breast, ovary and cervix. Ovarian, endometrial, and cervical cancers are three of the most common malignancies of the female reproductive organs (Snijders et al., 3009). CA 125 is historically the most reliable serum marker for ovarian cancer; it is usually elevated in $50 \%$ of early-stage ovarian tumors (Muinao et al., 2008). CA 15.3, however, has been reported to be the most commonly used tumor marker for breast cancers (Pasaoglu et al., 2007). It is thought that the cervix and ovary share the same embryonic origin thus the implication of CA 125 as one of the test biomarkers for this study. For comparison of effectiveness, CA 15.3 (widely used breast tumor marker) and CEA which is commonly used as a colorectal tumor marker was included in this study. 
CIN can be classified into CIN 1, CIN 2 and CIN 3 according to the thickness of the layer of cervical epithelium containing abnormal cells (Mishra et al., 2011) (Mishra et al., 2011). About 90\% of CIN 1 (early CIN) cases regress within two years while 5\% of CIN 2 (intermediate) and 40\% of CIN 3 (full -blown) cases develop into invasive cervical cancer (Brown et al.,2012). The 5-year survival rate of cervical cancer reaches $90 \%$ when it is detected early and treated appropriately. However, survival at the late stage is just $15-30 \%$ (Xu et al., 2018). Therefore, early detection of CIN is key to increasing the chances of survival. The aim of the study therefore, is to access the possibility for the use of CA125, 15.3 and CEA in the early diagnosis of cervical intraepithelial neoplasm.

\section{PARTICIPANTS AND METHODS}

A total of 197 participants were recruited for this study at the Urogynaecology and Gynae-oncology Unit of the Department of Obstetrics and Gynaecology, University of Benin Teaching Hospital (UBTH) between August 2017 and January, 2019. The biochemical analysis of the research participants was carried out at the Metabolic Research Unit of the Department of Chemical Pathology, Edo University Iyamho, Edo State, Nigeria. Cases included patients with histological diagnosis of cervical intraepithelial neoplasm and abnormal Pap smear referred from Gynaecology Clinic, General Practice Clinic, Community Development Clinic in University of Benin Teaching Hospital (UBTH) and also referrals for Colposcopy from private hospitals in Benin City. Control participants were selected from the Gynaecology clinic of UBTH and were patients with normal Colposcopy who matched the case for age and parity. Venipuncture was done for all the participants for the collection of blood sample for biochemical analysis. A measured $5 \mathrm{ml}$ of blood samples was collected into a plain tube, allowed to clot and retracted. Thereafter it was centrifuged at $2000 \mathrm{rpm}$ for 15 mins. The serum was collected with Pasteur pipette into a plain tube and then stored at about $-4{ }^{\circ} \mathrm{C}$ until the biochemical analysis was carried out. The biochemical analysis of CA125, CA15.3 and CEA were carried out using the enzyme- linked Immunosorbent Assay (ELISA) method described by Chretien et al. (1989).

\section{DATA ANALYSIS}

Data collected were analyzed using SPSS version 20. Results were presented using Tables, Plates and Graphs. Quantitative variables were expressed as mean \pm standard deviation, while categorical data were presented using frequencies and proportions.

\section{RESULTS}

The Socio-demographic information of the study participants showed that there was a total of 53 participants that were negative for CIN lesions, compared to 144 that had CIN lesion based on the histological diagnosis. Most of the participants in both control and CIN groups belonged to the $51-60$ yrs age category. More than $31 \%$ of the participants with a positive CIN histological result were smokers, compared to $13.2 \%$ in the control. $40.3 \%$ of women diagnosed with CIN had primary education. About $90 \%$ of the participants in the control group had at least a secondary education. $98.6 \%$ of the CIN group and $92.5 \%$ of the healthy group have been unsuccessful in conception. There was no significant difference between the groups for this risk factor (Table 1). 
The serum levels of the tumor markers presented showed significant differences among the various stages of CIN (Table 2). Fifty-three individuals were normal, compared to 45 participants with Stage 1 CIN. There were also 50 individuals in the group which had Stage $3 \mathrm{CIN}$. Generally, the serum levels of the test markers were lower in the normal individuals. CA125 levels increased from $8.89 \mathrm{ng} / \mathrm{ml}$ in the normal participants to $17.81 \mathrm{ng} / \mathrm{ml}$ in the individuals with Stage 3 CIN. Similarly, Stage 3 individuals had higher CA15.3 levels (49.46 ng/ml) as well as CEA levels $(17.43 \mathrm{ng} / \mathrm{ml})$, compared to their respective normal individuals. Generally, the serum levels of the tumor markers increased steadily as the Stages of CIN presentations also increased.

The mean, as well as the percentiles of each tumor marker within the study population, were compared (Table 3). For CA125, the $95^{\text {th }}$ percentile presented values that were higher than the statistic mean. This was so in the other markers used in the study, across the stages. The mean value for CA15.3 during stage 2 CIN presentation was 42.66 $\mathrm{ng} / \mathrm{ml}$ compared to $60.9 \mathrm{ng} / \mathrm{ml}$ which was the $95^{\text {th }}$ percentile value. Values obtained from the receiver operator curve that presented the sensitivities and specificities for CA 125, CA 15.3 and CEA in the biomarking of CIN against the gold standard have been presented on Figure 1, Table 4(a,b). The Area Under the Curve for CA125 was 85.4\%, and 90.0\% for CEA respectively ( $\mathrm{p}<0.05$ ) (Table $4 \mathrm{a}$ ). The cutoff value obtained for CA125 against the gold standard was $11.90 \mathrm{ng} / \mathrm{ml}$, whereas the benchmark serum value obtained for CA15.3 and CEA were $31.35 \mathrm{ng} / \mathrm{ml}$ and $11.65 \mathrm{ng} / \mathrm{ml}$ respectively (Table $4 b$ ).

The sensitivity of CA125 and CEA were statistically comparable (53.47-54.17\%). Both sensitivity values and negative predictive values were recorded for CA15.3 (Table 5). However, Specificities were more than 95\% for all three test markers. There was significant bivariate correlation between CA125 and CA15.3 ( $\mathrm{r}=0.493, \mathrm{p}=<0.001)$ as well as between CA125 and CEA $(r=0.325, p=<0.001)$ (Table 6). However, with a low Pearson's coefficient of correlation, these bivariate associations were statically reliable.

The study attempted to compare the capacities of the various test tumor markers to significantly isolate the CIN individuals from the study population compared to the gold standard (Table 7). According to the gold standard (Pap smear), 144 individuals in the study population were isolated for CIN occurrence - 45 with Stage 1, 49 with Stage 2 and 50 with Stage 3 CIN. Among these CIN individuals, CA15.3 could not identify any individual with CIN stages 1 and 2, thereby making it a very weak diagnostic tool. CA15.3 could only spot out those who were already on Stage 3 of the disease. However, CEA was able to identify $22.2 \%$ of Stage 1 individuals and $37 \%$ of Stage 2 sufferers.

\section{DISCUSSION}

This study highlighted evidence of the relationship between selected lifestyle patterns, serum markers and CIN status. About one third of the participants that were positive for CIN (using the gold standard) had a positive history of smoking. Smoking was a contributory factor to the percentage of CIN participants. Individuals with smoking habit were three times less in the control. However, studies have shown that age and smoking history influences the evaluation of CEA levels (Ghosh et al., 2013). CEA levels are more elevated in smokers and may translate into false positives or misleading diagnosis (Ghosh et al., 2013). This perhaps reemphasizes smoking as being a risk factor for CIN. The educational background of participants was suggested to be significant as a risk factor for CIN. There have 
been reports of several risk factors similar to those in this study contributing to the prevalence of cervical cancer (Arbyn et al., 2011).

There was an increasing pattern of the Cancer Antigen biomarkers (CA 125 and CA 15.3) as the intraepithelial neoplasm progressed. The levels of these serum markers were lower in the healthy participants. This finding is similar to the report by Pasaoglu and coworkers (Pasaoglu et al., 2007) in their research on diagnostic value of CEA, CA-19-9, CA 125 and CA 15-3 levels in malignant pleural fluids. However, according to National Comprehensive Cancer Network (NCCN), CA15.3 and CEA may not be used alone for the purpose of therapeutic decisions because increase serum levels can be as a result of disease progression and may occur due to responding disease. Serum levels of CA15.3 may increase due to the death of abnormal cells (Himanshu and Micheal, 2018).

Hoon and Mavanur (2013) reported that CA15.3 assay was helpful in-patient monitoring with better clinical sensitivity than CEA. This, they thought to be an advantage over CEA because CA15.3 levels are not abnormally elevated in smokers. Though, CA15.3 was stated unsuitable as an early diagnostic tool for its low sensitivity to premalignant lesions. However, records suggest that combined use of CA15.3 and CEA does not give improved clinical information (Hoon and Mavanur, 2013).

The receiver operator curve (ROC) in the present study placed the benchmark for CA 125, CA 15.3 and CEA at levels of diagnosing CIN 2, CIN I and CIN 2 respectively but the observations from the laboratory analysis showed that CA 15.3 did not detect premalignant lesions until it was at CIN 3 (Figure 1). This suggests a clear evidence of a poor early biomarker. CA 15-3, however is thought to be an ideal marker for breast cancer and has been evaluated for malignant pleural effusions. Another study found CA 15-3 level to be higher in patients with metastatic cancer compared to that of mesothelioma cases (Mezger et al., 1994, Shitrit et al., 2010)). Ghayumi and colleagues in 2005 determined CA15-3 as a marker with high sensitivity and specificity (70\% and 83.3\%, respectively) for differentiating malignant and benign pleural effusions of some Iranian patients (Ghayumi et al, 2005).

In the present study, the cut off value for sick women according to the ROC for CA 15.3 was $31.35 \mathrm{ng} / \mathrm{ml}$ whereas within the gold standard detected healthy population, the mean CA 15.3 level was $32.18 \mathrm{ng} / \mathrm{ml}$ (see Table 2 and $4 \mathrm{~b}$ ). This observation is not a good indicator for recommending CA 15.3 as an ideal biomarker. Findings from the assessment of CA125 and CEA as biomarkers for very early CIN in this study prove that these serum markers could give misleading diagnosis compared to when the gold standard was used. Only $13.3 \%$ of the 45 participants diagnosed with CIN 1 according to the Pap smear test were detected by CA125 and 22\% identified by CEA. It can be deduced that using CA125 and CEA as a diagnostic biomarker for the early stage of CIN will create a very high percentage of false negatives. CA15.3 however, gave a clear-cut diagnosis of CIN 3 which was the exact diagnosis from the gold standard test. This study therefore suggests CA15.3 as a more specific biomarker than CA125 and CEA for CIN due to its specific unsuitability in detecting CIN at stages 1 and 2, and accurate diagnosis of CIN 3 participants. Kandylis et al. (1990) also reported that CA15.3 is a biomarker with definite diagnostic accuracy compared to CEA and CA125 in breast cancer (Kandylis et al., 1990).

This research included a comparison of sensitivities and specificities of the three biomarkers under study against the gold standard. CEA and CA 125 were found to be weakly sensitive to CIN (54.7\% and $53.47 \%$ ) but 98 $\%$ and $100 \%$ specific to the disease respectively. CA 15.3 was totally insensitive to CIN 1 and 2 with a Positive 
Predictive Value (PPV) of $0.00 \%$. The Negative Predictive Values (NPV) of the three biomarkers studied were generally low though CEA and CA 125 were comparable (44. $17 \%$ and $44.05 \%)$. In general, the Pap smear test identified 144 women with CIN while CA 125 identified 77 women, CEA identified 78 women and CA 15.3 identified 50 women living with CIN (see Table 7). It is imperative that health workers should not rely solely on these biomarkers for clinical diagnosis of early stage CIN as reported in this study. However, CA 15.3 may be used solely for monitoring patients diagnosed with CIN 2 in order to evaluate progression or regression during therapy.

\section{CONCLUSION}

Effective prediction of a condition as critical as CIN is of utmost importance in cancer research. The continuous search for appropriate serum markers for early diagnosis is due to the massive mortality rate recorded from cervical cancer in recent years. This research finds CA 125, CA 15.3 and CEA unsuitable for arbitrary population screening because of low sensitivity and high risk for false negatives. However, this study recommends CA 15.3 as a biomarker to be used as a monitoring tool for CIN 2 patients in clinical prognostics. 
Table 1: Socio-demographic characteristics of the study population

\begin{tabular}{|c|c|c|c|c|c|c|c|c|}
\hline & & \multicolumn{2}{|c|}{ CIN group $(n=144)$} & \multicolumn{2}{|c|}{$\begin{array}{l}\text { Control group } \\
(n=53)\end{array}$} & \multirow[t]{2}{*}{ df } & \multirow[t]{2}{*}{$\mathrm{X}^{2}$} & \multirow[t]{2}{*}{$\begin{array}{l}\mathrm{p}- \\
\text { value }\end{array}$} \\
\hline & & (n) & $(\%)$ & (n) & $(\%)$ & & & \\
\hline \multirow[t]{4}{*}{ CIN.Staus } & Normal & 0 & 0.0 & 53 & 26.9 & \multirow[t]{4}{*}{3.0} & \multirow[t]{4}{*}{0.463} & \multirow[t]{4}{*}{0.925} \\
\hline & Stage 1 & 45 & 22.8 & 0 & 0.0 & & & \\
\hline & Stage 2 & 49 & 24.9 & 0 & 0.0 & & & \\
\hline & Stage 3 & 50 & 25.4 & 0 & 0.0 & & & \\
\hline \multirow[t]{5}{*}{ Age group } & $31-40$ yrs & 17 & 11.8 & 15 & 28.3 & \multirow[t]{5}{*}{4.0} & \multirow[t]{5}{*}{5.784} & \multirow[t]{5}{*}{0.216} \\
\hline & $41-50$ yrs & 32 & 22.2 & 10 & 18.9 & & & \\
\hline & $51-60$ yrs & 56 & 38.9 & 20 & 37.7 & & & \\
\hline & $61-70$ yrs & 10 & 6.9 & 8 & 15.1 & & & \\
\hline & $>70 \mathrm{yrs}$ & 29 & 20.1 & 0 & 0.0 & & & \\
\hline \multirow{3}{*}{$\begin{array}{l}\text { Educational } \\
\text { Stage }\end{array}$} & Primary Edu. & 58 & 40.3 & 5 & 9.4 & \multirow[t]{3}{*}{2.0} & \multirow[t]{3}{*}{2} & \multirow[t]{3}{*}{0.368} \\
\hline & Secondary Edu. & 16 & 11.1 & 26 & 49.1 & & & \\
\hline & Tertiary Edu. & 70 & 48.6 & 22 & 41.5 & & & \\
\hline \multirow[t]{9}{*}{ Parity } & 1.00 & 0 & 0.0 & 9 & 17.0 & \multirow[t]{9}{*}{8.0} & \multirow[t]{9}{*}{11.501} & \multirow[t]{9}{*}{0.175} \\
\hline & 2.00 & 6 & 4.2 & 0 & 0.0 & & & \\
\hline & 3.00 & 24 & 16.7 & 11 & 20.8 & & & \\
\hline & 4.00 & 38 & 26.4 & 17 & 32.1 & & & \\
\hline & 5.00 & 32 & 22.2 & 6 & 11.3 & & & \\
\hline & 6.00 & 19 & 13.2 & 8 & 15.1 & & & \\
\hline & 7.00 & 0 & 0.0 & 2 & 3.8 & & & \\
\hline & 8.00 & 22 & 15.3 & 0 & 0.0 & & & \\
\hline & 11.00 & 3 & 2.1 & 0 & 0.0 & & & \\
\hline Unsuccessfu & .00 & 142 & 98.6 & 49 & 92.5 & \multirow[t]{4}{*}{3.0} & \multirow[t]{4}{*}{4.386} & \multirow[t]{4}{*}{0.223} \\
\hline \multirow[t]{3}{*}{1 conception } & 1.00 & 0 & 0.0 & 4 & 7.5 & & & \\
\hline & 2.00 & 1 & .7 & 0 & .0 & & & \\
\hline & 7.00 & 1 & .7 & 0 & .0 & & & \\
\hline \multirow{2}{*}{$\begin{array}{l}\text { Marriage } \\
\text { type }\end{array}$} & Monogamy & 127 & 88.2 & 37 & 69.8 & \multirow[t]{2}{*}{1.0} & 2.4 & 0.121 \\
\hline & Polygamy & 17 & 11.8 & 16 & 30.2 & & & \\
\hline Smoking & Smokers & 46 & 31.9 & 7 & 13.2 & 1.0 & 2.4 & 0.121 \\
\hline habit & Non Smokers & 98 & 68.1 & 46 & 86.8 & & & \\
\hline History of & No history & 66 & 45.8 & 24 & 45.3 & 4.0 & 5.564 & 0.234 \\
\hline usage of & $<1 \mathrm{yr}$ & 68 & 47.2 & 9 & 17.0 & & & \\
\hline $\mathrm{OCP}$ & $1-3 \mathrm{yrs}$ & 4 & 2.8 & 5 & 9.4 & & & \\
\hline & $4-6 \mathrm{yrs}$ & 0 & 0.0 & 12 & 22.6 & & & \\
\hline & $>6 \mathrm{yrs}$ & 6 & 4.2 & 3 & 5.7 & & & \\
\hline
\end{tabular}


Table 2: Serum levels of tumor markers at the various stages of CIN in the study population

\begin{tabular}{ccccc}
\hline & $(\mathrm{n})$ & CA125 & CA15.3 & CEA \\
\cline { 3 - 5 } & & & $(\mathrm{ng} / \mathrm{ml})$ \\
\hline Normal & 53 & $8.89^{\mathrm{a}}$ & $32.18^{\mathrm{a}}$ & $11.57^{\mathrm{ab}}$ \\
Stage 1 & 45 & $10.72^{\mathrm{a}}$ & $37.42^{\mathrm{ab}}$ & $11.00^{\mathrm{a}}$ \\
Stage 2 & 49 & $15.88^{\mathrm{b}}$ & $42.66^{\mathrm{bc}}$ & $12.58^{\mathrm{b}}$ \\
Stage 3 & 50 & $17.81^{\mathrm{b}}$ & $49.46^{\mathrm{c}}$ & $17.43^{\mathrm{c}}$ \\
& & & & \\
F statistic & - & 18.719 & 5.559 & 35.211 \\
p-value & - & $<0.001$ & .001 & $<0.001$ \\
\hline
\end{tabular}

Table 3: Comparative presentations of means and percentiles of tumor markers at the various stages of CIN in the study population.

\begin{tabular}{|c|c|c|c|c|c|c|c|}
\hline \multirow{2}{*}{\multicolumn{2}{|c|}{$\begin{array}{c}\text { Descriptive } \\
\text { Statistics }\end{array}$}} & \multirow[t]{2}{*}{ Normal } & \multicolumn{3}{|c|}{ CIN } & \multirow[t]{2}{*}{ F- statistic } & \multirow[t]{2}{*}{ p-value } \\
\hline & & & Stage 1 & Stage 2 & Stage 3 & & \\
\hline \multicolumn{8}{|c|}{$C A 125$} \\
\hline \multicolumn{2}{|l|}{ (n) } & 53.0 & 45.0 & 49.0 & 50.0 & & \\
\hline \multicolumn{2}{|c|}{ Mean } & 6.33 & 9.41 & 15.88 & 17.81 & 37.941 & $<0.001$ \\
\hline \multicolumn{2}{|c|}{ Skewness } & 0.11 & 0.41 & 0.38 & 2.2 & & \\
\hline \multicolumn{2}{|c|}{ Kurtosis } & -0.41 & 0.82 & -1.57 & 4.43 & & \\
\hline \multirow[t]{3}{*}{ Percentiles } & 75 th & 8.1 & 10.6 & 25.8 & 17.8 & & \\
\hline & 85 th & 9.4 & 11.67 & 25.8 & 24 & & \\
\hline & 95th & 11.06 & 16 & 27 & 42 & & \\
\hline \multicolumn{8}{|c|}{ CA 15.3} \\
\hline \multicolumn{2}{|c|}{ Mean } & 22.49 & 29.33 & 42.66 & 52.73 & 14.231 & $<0.001$ \\
\hline \multicolumn{2}{|c|}{ Skewness } & 0.08 & -0.12 & 0.05 & 0.65 & & \\
\hline \multicolumn{2}{|c|}{ Kurtosis } & -0.8 & -1.41 & -1.93 & 1.83 & & \\
\hline \multirow[t]{3}{*}{ Percentiles } & 75 th & 31.3 & 40.2 & 58.3 & 62.1 & & \\
\hline & 85 th & 34.6 & 43.77 & 60.9 & 65.58 & & \\
\hline & 95th & 38.1 & 47.9 & 60.9 & 85.85 & & \\
\hline \multicolumn{8}{|c|}{$\boldsymbol{C E A}$} \\
\hline \multicolumn{2}{|c|}{ Mean } & 6.16 & 11 & 12.58 & 17.43 & 79.43 & $<0.001$ \\
\hline \multicolumn{2}{|c|}{ Skewness } & 0.19 & -0.06 & 0.4 & 0.37 & & \\
\hline \multicolumn{2}{|c|}{ Kurtosis } & -1.24 & -0.79 & -1.69 & -1.83 & & \\
\hline Percentiles & 75 th & 9.15 & 11.3 & 15.2 & 25.3 & & \\
\hline & 85 th & 9.6 & 12.15 & 15.2 & 25.3 & & \\
\hline & 95th & 10.8 & 12.6 & 15.2 & 25.3 & & \\
\hline
\end{tabular}




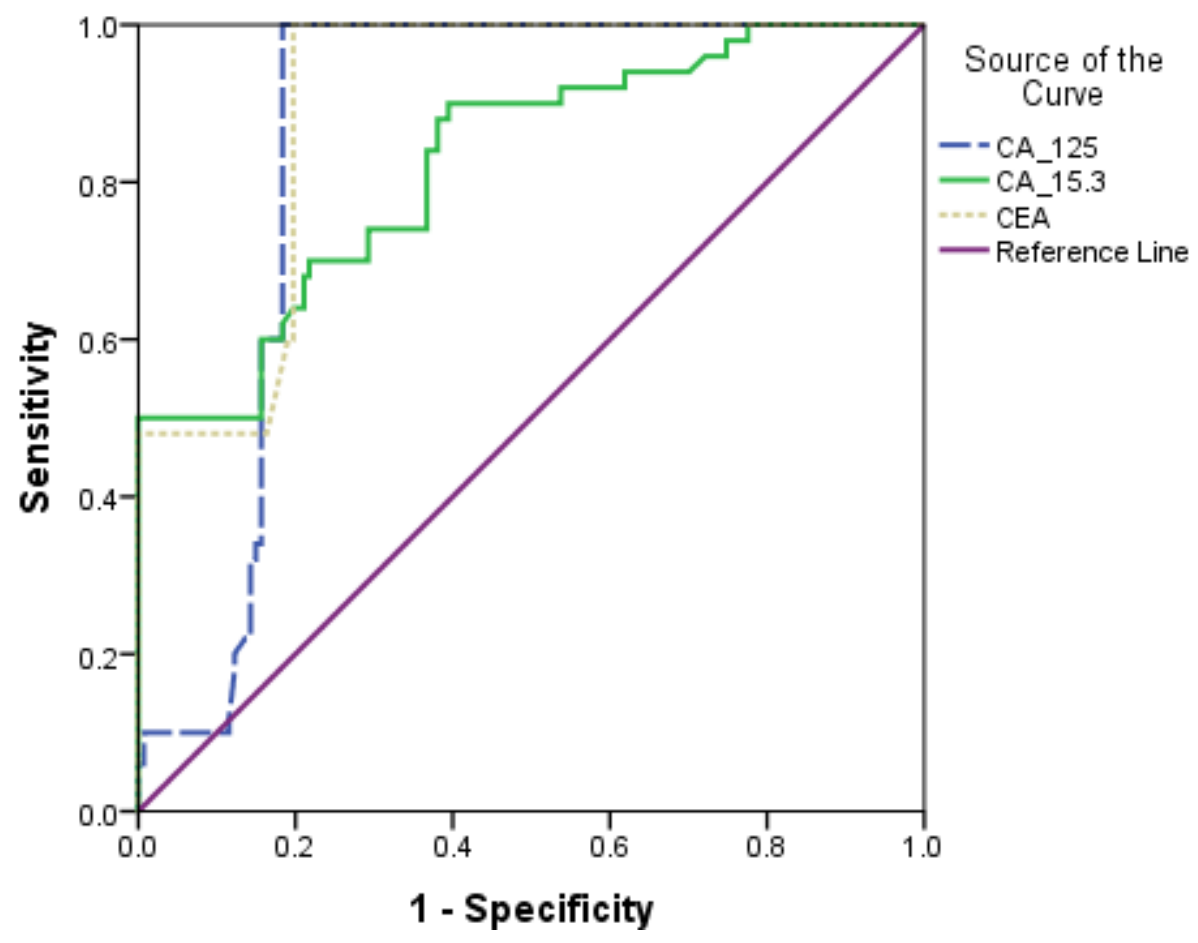

Figure 1: Receiver operator curve presenting sensitivities and specificities for CA 125, CA 15.3 and CEA in the biomarking of CIN against the gold standard (Pap smear)

Table 4(a): Area under the curve for ROC presented for sensitivities and specificities for CA 125, CA 15.3 and CEA in the biomarking of CIN against the gold standard (Pap smear).

\begin{tabular}{lccccc}
\hline \multicolumn{5}{c}{ Area Under the Curve } \\
\hline Test Result & Area & Std. Error & Asymptotic & \multicolumn{2}{c}{ Asymptotic 95\% CI } \\
\cline { 5 - 6 } Variable(s) & & & Sig. & Lower Bound & Upper Bound \\
\hline CA_125 & 0.854 & 0.027 & $<0.001$ & 0.800 & 0.907 \\
CA_15.3 & 0.825 & 0.035 & $<0.001$ & 0.757 & 0.892 \\
CEA & 0.900 & 0.022 & $<0.001$ & 0.857 & 0.942 \\
\hline
\end{tabular}


Table 4(b): Abridged coordinates of the curve for ROC presented for sensitivities and specificities for CA 125, CA 15.3 and CEA in the biomarking of CIN against the gold standard (Pap smear).

\begin{tabular}{|c|c|c|c|c|c|c|c|c|c|c|c|}
\hline \multicolumn{12}{|c|}{ Coordinates of the Curve } \\
\hline \multicolumn{4}{|c|}{ CA_125 } & \multicolumn{4}{|c|}{ CA_15.3 } & \multicolumn{4}{|c|}{$\overline{C E A}$} \\
\hline POS & Sens. & $\begin{array}{l}1- \\
\text { Spec }\end{array}$ & $\Delta$ & POS & Sens. & 1-Spec & $\Delta$ & POS & Sens. & $\begin{array}{l}1- \\
\text { Spec }\end{array}$ & $\Delta$ \\
\hline .40 & 1.00 & 1.00 & 0.00 & 3.30 & 1.00 & 1.00 & 0.00 & .50 & 1.00 & 1.00 & 0.00 \\
\hline 1.60 & 1.00 & 0.99 & 0.01 & 4.60 & 1.00 & 0.99 & 0.01 & 1.65 & 1.00 & 0.99 & 0.01 \\
\hline 1.85 & 1.00 & 0.99 & 0.01 & 7.20 & 1.00 & 0.97 & 0.03 & 10.35 & 1.00 & 0.54 & 0.46 \\
\hline 2.55 & 1.00 & 0.98 & 0.02 & 10.35 & 1.00 & 0.97 & 0.03 & 10.60 & 1.00 & 0.45 & 0.55 \\
\hline 3.35 & 1.00 & 00.93 & 0.07 & 15.45 & 1.00 & 0.81 & 0.19 & 11.00 & 1.00 & 0.44 & 0.57 \\
\hline 3.55 & 1.00 & 0.93 & 0.08 & 16.20 & 1.00 & 0.80 & 0.20 & 11.25 & 1.00 & 0.37 & 0.63 \\
\hline 3.80 & 1.00 & 0.92 & 0.08 & 26.90 & 0.92 & 0.61 & 0.32 & 11.45 & 1.00 & 0.31 & 0.69 \\
\hline 11.40 & 1.00 & 0.19 & 0.81 & 27.90 & 0.92 & 0.56 & 0.36 & $11.65^{* *}$ & 1.00 & 0.20 & 0.80 \\
\hline $11.90 * *$ & 1.00 & 0.18 & 0.82 & 28.85 & 0.92 & 0.54 & 0.38 & 11.85 & 0.60 & 0.20 & 0.40 \\
\hline 12.60 & 0.90 & 0.18 & 0.72 & 29.60 & 0.90 & 0.54 & 0.36 & 12.05 & 0.60 & 0.19 & 0.41 \\
\hline 13.05 & 0.60 & 0.18 & 0.42 & 30.60 & 0.90 & 0.43 & 0.47 & 12.35 & 0.48 & 0.16 & 0.32 \\
\hline 16.15 & 0.32 & 0.15 & 0.17 & $31.35 * *$ & 0.90 & 0.39 & 0.51 & 13.90 & 0.48 & 0.12 & 0.36 \\
\hline 17.05 & 0.32 & 0.14 & 0.18 & 31.70 & 0.88 & 0.39 & 0.49 & 16.00 & 0.48 & 0.00 & 0.48 \\
\hline 18.35 & 0.22 & 0.14 & 0.08 & 32.15 & 0.88 & 0.39 & 0.49 & 21.05 & 0.38 & 0.00 & 0.38 \\
\hline 46.00 & .00 & 0.00 & 0.00 & 122.00 & .00 & 0.00 & 0.00 & 26.30 & 0.00 & 0.00 & 0.00 \\
\hline
\end{tabular}

Table 5: Comparative sensitivities and specificities of CA 125, CA 15.3 and CEA in the biomarking of CIN against the gold standard.

\begin{tabular}{lccc}
\hline & CA_125 & CA_15.3 & CEA \\
\cline { 2 - 4 } & \multicolumn{3}{c}{$(\%)$} \\
\hline Sensitivity & 53.47 & 0.00 & 54.17 \\
Specificity & 100.00 & 100.00 & 98.11 \\
PPV & 100.00 & 0.00 & 98.73 \\
NPV & 44.17 & 26.91 & 44.05 \\
Prevalence & 73.09 & 73.09 & 73.09 \\
Likelihood Ratio & 64.71 & NA & 56.78 \\
Linear-by-Linear Association & 46.29 & NA & 43.86 \\
\hline
\end{tabular}

Table 6: Bivariate correlation among the tumor markers in the diagnosis of CIN against the gold standard

\begin{tabular}{lcc}
\hline & \multicolumn{2}{c}{ CA.125 } \\
\cline { 2 - 3 } & $\mathrm{R}$ & $\mathrm{P}$ \\
\hline CA_15.3 & $0.493^{* *}$ & $<0.001$ \\
CEA & $0.325^{* *}$ & $<0.001$ \\
\hline
\end{tabular}

**. Correlation is significant at the 0.01 Stage (2-tailed). 
Table 7: Comparative capacity of the 3 test tumor markers for identifying CIN among the CIN group originally separated by the gold standard

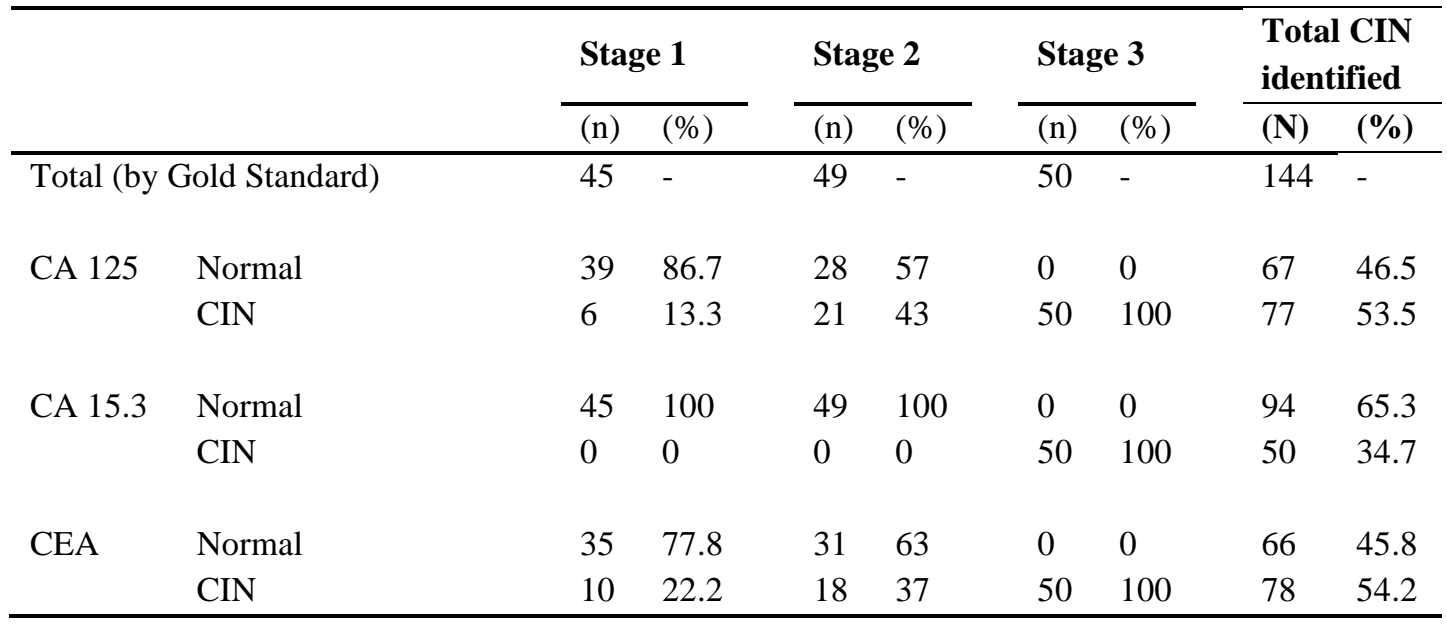

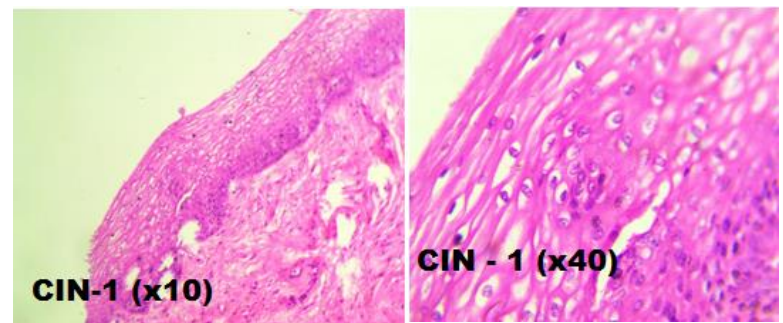

(a)

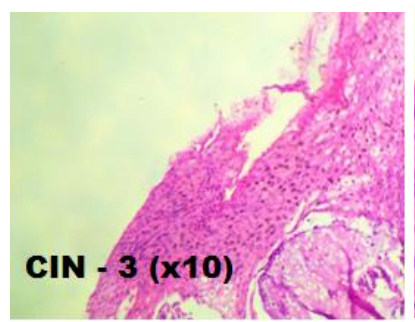

(e) (b)

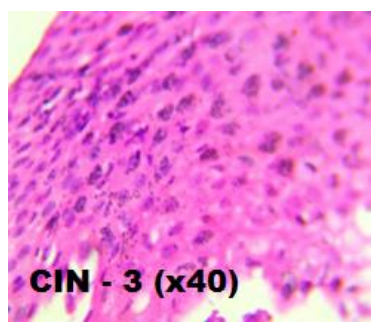

(f)

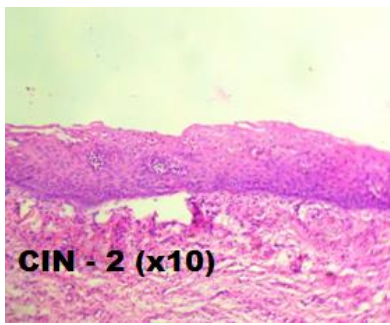

(c)

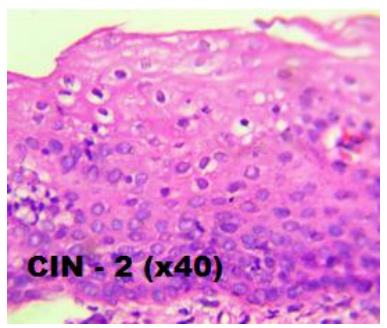

(d)

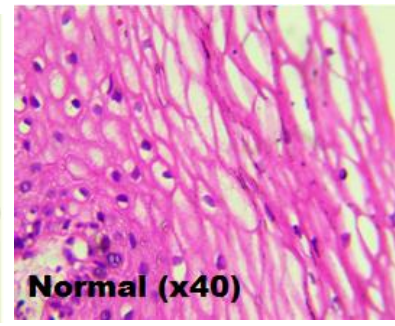

(h)

Plate 1: Sections showing dysplastic squamous epithelial cells involving the lower third of the ectocervix at (a) x10 and (b) x40 magnification, the lower two-thirds of the ectocervix at (c) x10 and (d) x40 magnification, and the full thickness of the ectocervix at (e) x10 and (f) x40 magnification, as well as normal squamous epithelial cells lining the ectocervix at (g) x10 and (h) x40 


\section{REFERENCES}

Arbyn, M., Castellsagu'e, X., and de sanjos'e S. Worldwide burden of cervical cancer in 2008.c Annals of Oncology,2011; 22 (12): $2675-2686$

Bosch, F. X., Burchell, A. N., Schiffman, M., Giuliano, A. R., de Sanjose, S., Bruni, L., Tortolero-Luna, G., Kjaer, S. K. and Munoz, N. Epidemiology and natural history of human papillomavirus infections and type-specific implications in cervical neoplasia. Vaccine, 2008;26: K1-16.

Brown, C. A., Bogers, J., Sahebali, S., Depuydet, C. E., De Prins, F. and Malinowski, D. P. Role of protein biomarkers in the detection of high-grade disease in cervical cancer screening programs. Journal of Oncology, 2012;289315. DOI:10.1155/2012/289315.

Chretien, I., Van Kimmenade, A., Pearce, M., Banchereau, J. and Abrams, J. S. Development of polyclonal and monoclonal antibodies for immunoassay and neutralization of human interleukin- 4. Journal Immunology Methods, 1989; 117:67-73.

Dasari, S., Wudayagiri, R. and Valluru, L. Cervical cancer: Biomarkers for dignosi nd treaent. Clinica Chimica Acta,2015; 445:7-11.

Ferlay, J., Shin, H. R., Bray, F., Forman, D., Mathers, C. and Parkin, D. M. Estimates of worldwide burden of cancer in 2008: GLOBOCAN2008," International Journal of Cancer,2010; 127: (12) 2893 - 2917

Ghayumi, S. M., Mehrabi, S., Doroudchi, M. and Ghaderi, A. Diagnostic value of tumor markers for differentiating malignant and benign pleural effusions of Iranian patients. Pathology Oncology Research, 2005;11(4):236 410.

Ghosh, I. Bhattacharjee, D. Das, A. K. Chakrabarti, G. Dasgupta A. and Dey, S. K. Diagnostic Role of Tumour Markers CEA, CA15-3, CA19-9 and CA125 in Lung Cancer. Indian Journal of Clinical Biochemistry,2013; 28(1):24-29. DOI 10.1007/s12291-012-0257-0.

Goncalves, J. E. S., Andrade, C.V., Russomano, F. B., Nuovo, G. J., Amaro-Filho, S. M., Carvalho, M. O. O. and Nicol, A. F. The role of p16 as putative biomarker for cervical neoplasia: A controversial issue. Medical Express, 2017;4 (6): M170601

Himanshu, J. and Micheal, F. P. Molecular oncology of breast cancer. In: The breast: comprehensive management of benign and malignant diseases. $5^{\text {th }}$ edition. 2018; 1136p.

Hoon, H. S., Mavanur, R. S. Cancer markers. In: The immunoassay handbook. ed: David Wild, 4th edition.2013; 1036p.

Jastreboff, A. M. and Cymet, T. Role of the human papilloma virus in the development of cervical intraepithelial neoplasia and malignancy. Postgraduate Medical Journal, 2002;78: 225-228.

Jemal, A., Bray, F. and Forman, D. Cancer burden in Africa and opportunities for prevention. Cancer, 2012; 118 (18): 4372 - 4384.

Kandylis, K., Vassilomanolakis, M., Baziotic, N., Papadimitriou, A., Tsoussis, S., Ferderigou, A. and Efremidis, A. P. Diagnostic significance of the tumor markers CEA, CA15.3 \& CA125 in malignant effusions in breast cancer. Annal Oncology, 1990;1(6): 435 - 438.

Mezger, J., Calavrezos, A.and Drings, P.. Value of serum and effusion fluid CEA levels for distinguishing between diffuse malignant mesothelioma and carcinomatous pleural metastases. Lung, 1994;172 (3):183-400 Mishra, G. A., Pimple, S. A. and Shastri, S. S. An overview of prevention and early detection of cervical cancers. Indian Journal of Medicine Paediatric Oncology, 2011;32: 125-132.

Muinao, T., Prasanna, H., Boruah, D. and Pal, M. Diagnostic and Prognostic Biomarkers in ovarian cancer and the 
potential roles of cancer stem cells - An updated review. Experimental Cell Research, 2018;362 (1): 1-10. https://doi.org/10.1016/j.yexcr.2017.10.018

Pasaoglu, G., Zamani, A., Can, G. and İmecik, O. Diagnostic value of CEA, CA-19-9, CA 125 and CA 15-3 levels in malignant pleural fluids. European Journal of Gen Medicine, 2007;4(4):165-171.

Shitrit, D., Zingerman, B., Shitrit, A. B., Shlomi, D. and Kramer, M. R. Diagnostic value of CYFRA 21-1, CEA, CA 19-9, CA 15-3, and CA 125 assays in pleural effusions: analysis of 116 cases and review of the literature. Oncologist, 2005;10 (7):501-700.

Snijders, P. J., Steenbergen, R. D., Heideman, D. A. and Meijer, C. J. HPV-mediated cervical carcinogenesis: concepts and clinical implications. Journal of Pathology,2006; 208:152 - 164.

Vaccarella, S., Lortet-Tieulent, J., Plummer, M., Franceschi, S. and Bray, F. Worldwide trends in cervical cancer incidence: impact of screening against changes in disease risk factors," European Journal of Cancer, 2013;49

(15): 3262 - 3273.

World Health Organization. (2010). Human papillomavirus (HPV). Geneva

Xu, G., Fan, W., Wang, F., Lu, H., Xing, X., Zhang, R. and Jiang, P. CTHRC1 as a novel biomarker in the diagnosis of cervical squamous cell carcinoma. International Journal of Clinical Experimental Pathology, 2018; 11(2): $847-854$. 